\title{
Encerrando e protegendo: a Lepra no século XIV em Portugal
}

\author{
Carlos Roberto Figueiredo Nogueira ${ }^{1}$ \\ Professor Sênior FFLCH USP \\ crfnogue@usp.br
}

Como citar este artigo: Nogueira, C. R. F. "Encerrando e protegendo: a Lepra no século XIV em Portugal". Khronos, Revista de História da Ciência, nº, pp. 79-91. 2018. Disponível em <http://revistas.usp.br/khronos>. Acesso em $\mathrm{dd} / \mathrm{mm} /$ aaaa

Resumo: No século XIV a Crise impõe a escassez. Um Portugal já debilitado por uma balança comercial desfavorável foi marcado por crises de abastecimento e pestes, à parte de seu envolvimento constante guerras com Castela. Ou seja, foi um século de falta de pão, de devastações e pilhagens. No entanto, os leprosos parecem escapar à carestia generalizada.

Palavras-chave: Lepra, Portugal, século XIV.

\section{Enclosing and protecting: Leprosy in the fourteenth century in Portugal}

\begin{abstract}
In the fourteenth century a Crisis imposed a great shortage. Portugal has already been weakened by an unfavorable trade balance to be marked by crises of supply and pests, apart from its constant involvement in the wars with Castile. That is, it was a moment of lack of bread, of devastation and plunderers. However, lepers seem to escape the widespread scarcity.
\end{abstract}

Keywords: Leprosy, Portugal, fourteenth century.

A Lepra. Uma doença milenar que aflige a humanidade ganha, entretanto, uma nova relação com o sagrado no decorrer da Idade Média. Sendo o corpo o lugar do pecado, a evolução da enfermidade ao desfigurar o indivíduo afasta-o da imagem e da semelhança de Deus. Os leprosos constituem-se na permanente dessemelhança divina, a imagem viva do pecado.

\footnotetext{
${ }^{1}$ Professor Sênior e Ex-professor Titular da Universidade de São Paulo e Decano do Departamento de História. Acadêmico correspondente da Academia Portuguesa da História e coordenador do GEMPO, ligado à Cátedra Jaime Cortesão da Universidade de São Paulo.
} 
Excluídos do convívio dos homens esses doentes carregam consigo toda a contradição do imaginário medieval: de um lado, exemplos explícitos do pecado de outros "bem-aventurados" que por meio da doença o penitenciam em vida, deixando implícito seu lugar garantido no Reino dos Céus. A comunidade os afasta, mas não para muito longe: as leprosarias devem estar situadas "a um tiro de pedra da cidade"2.

Os homens medievais necessitam de seus desfigurados, afastados a curta distância para evitar o contágio, mas não tão distantes que não lhes permita exercer a caridade (tão obrigatória quanto necessária) e, ao mesmo tempo, observar o quão longe podem levar os pecados e a amarga punição imposta pela justiça divina.

Do ponto de vista da medicina medieval, a causa da lepra era baseada - para os médicos da Antiguidade e, portanto, para a Idade Média, na teoria dos humores. Segundo esta teoria, a saúde dependia do equilíbrio dos quatro humores do organismo, a saber: o sangue, a fleuma, a atrabilis (ou bílis negra) e a bílis. Pelo contrário, o seu desequilíbrio - provocava a doença. No caso específico da lepra, esta era causada por um excesso de atrabílis, que fazia dela uma doença melancólica ${ }^{3}$.

Na manutenção do equilíbrio humoral, a ingestão de certos alimentos restabelecia os humores. Deste modo, seguindo a explicação de Carole Rawcliffe, os alimentos consumidos pelos leprosos deviam ter uma natureza temperada, suave e úmida, para serem facilmente absorvidos pelo sistema digestivo sobreaquecido, devendo, por isso, serem evitados os produtos quentes ${ }^{4}$.

A preocupação com alimentação no tratamento da lepra é sumamente importante na remissão ou na estabilização da doença, mas, no século XIV, a Crise impõe a escassez. Um Portugal já debilitado por uma balança comercial desfavorável foi marcado por crises de abastecimento e pestes, à parte de seu envolvimento constante em guerras com Castela ${ }^{5}$. Ou seja, foi um século de falta de pão, de devastações e pilhagens. No entanto, os leprosos parecem escapar à carestia generalizada.

\section{Gafos e gafarias e os monarcas portugueses}

\footnotetext{
${ }^{2}$ LE GOFF, Jacques. O Maravilhoso e O Quotidiano no Ocidente Medieval. Lisboa: Edições 70, 1985, p. 183.

${ }^{3}$ RAWCLIFFE, Carole. Leprosy in Medieval England. Woodbrige, The Boydell Press, 2006, pp. 64-72.

${ }^{4}$ Ibid., p. 213.

${ }^{5}$ Ver SERRÃO, Joel. O carácter social da revolução de 1383. 2a. ed. Lisboa:, Livros Horizonte, 1976.
} 
Os gafos sempre estiveram sob a proteção dos reis portugueses. A Chancelaria de D. Dinis contém registros de 1279 a 1291, que refletem a proteção concedida aos gafos de Santarém e de Évora contra todos os que, em função da sua debilidade, os vexavam ou deles e de seus bens se aproveitavam. A intervenção da Coroa concernente aos gafos do reino foi muito intensa por toda esta época e manifestou-se desde medidas protetivas, até a dotação de 16 regimentos para institutos de fundação régia, como sucedeu com o Regimento de Afonso IV para o Hospital de S. Lázaro de Coimbra, até a criação de gafarias régias por todo o reino ${ }^{6}$.

Como exemplo maior, está o Regimento da Gafaria do Hospital de São Lázaro de Coimbra promulgado por Afonso IV em 1329:

\section{Regimento da Gafaria do Hospital de São Lázaro de Coimbra.}

[fl. 1] Este he o livro en que he scripta a ordinbagom que El Rey fer.per que sejam manteudos os gaffos, as gaffas e os mercieiros saos da Gaffaria de Coimbra.

E em este livro som scriptos os foros e os custumes que os gaffos am. E as pitansas e as festas que amd' aver. E em este livro som scriptas as herdades e possissoes que a gaffaria baa tambem aldeas como herdades que ba em Campo de Mondego e fora del. Tambem cassas come vinhas e olivaaes e almuynhas. E os moinhos e a renda deles. E o tempo a que am-de pagar as rendas delas e os foros que am a dar das aldeas e o tempo a que os ham a dar. E a raçom que am a dar de pam e de vinho e dasoutras coussas que Deus by der nas dictas aldeas e herdades e possissĩes.

\section{Titollo primeiro que falla da hordinhaçom.}

Em nome de Deus amen. Era de mil CCC e sessaenta e vii anos. Dom Afonso o quarto rey de Portugal e do Algarve seendo el na cidade de Coimbra os gaffos e as gaffas e os mercieiros saos lhy fezeromquerella que nom eram bem mantehudos segundo as herdades e as possissoes e as rendas que a dita Gaffaria avya. Eo dicto senhor rey a piticam dos dictos gaffos quis saber todallas cousas que a dicta gaffaria avya naquel tenpo. Tambem herdades come todallas as possissoes. E as rendas dellas tambem de pam come de vinho come de dinbeiros e das outras coussas todas. E foy certo que os gaffos lhe deziam verdade e querendo-lhis far[er] graça [e] merce fez esta ordinhaşão per que fosen mantehudos os dictos gafos gafas e mercieiros. Que tal he:

[1] Primeiramente manda El Rey que dem a cada buum gaffo e algunns a que el fer. mercee que am tal racom como huum dos gaffos cada ano ii moyos de trigo, ii quarteiros de segunda.

[2] Item manda que enquanto durar o vinho na adega que lhe dem cada dia bua meya e meya doutra meya de vinho.

[3] Item manda El Rey que des que sayr o vinho que lhe dem cada dia oyto dinheiros a cada buum pera vinho.

[4] Item manda que lhe $<$ dem $>$ a cada buum por primeiro dia de Janeiro viii libras pera vestire, xxii soldos pera lenba. E buum alqueire d' azeyte e buum alqueire de sal.

${ }^{6}$ Portugaliae Monumenta Misericordiarum / ed. lit. Centro de Estudos de História Religiosa da Universidade Católica Portuguesa; coord. científico José Pedro Paiva. Lisboa: União das Misericórdias Portuguesas, 2002, vol. 2., pp. 15-16. 
[5] Item manda El Rey que des que sayr o trigo do celeiro que dem segunda dobrada. E se by nom ouver segunda que avonde manda El Rey que o veedor da Gaffaria o compre. E se nom ouver tantos dinheiros que avondem pera comprar o dicto pam, manda El Rey que lho entregem a novo.

[6] Item manda El Rey que aja by huum veedor e huum scrivam que seja clerigo de missa e que cante tres dias da domaa missa na egreja da Gaffaria. E que escreva a recepta e a despesa que se na Gaffaria fezer. E o veedor pera procurar os beens da dicta Gaffaria e pera dar as rações aos gaffos e aos merceeiros sãos ao tenpo como El Rey manda em esta hordinhaçom.

Outrosy he tehudo se os dinheiros das rendas nom ouverem tam agi/ / [fl. $1 \mathrm{v}]$ aginha pera procurar os bees da dicta gaffaria e pera dar as rações aos gaffos e aos mercieiros saos ao tempo como El Rey manda em esta hordinhacom.

[7] Outrosy he tehudo se os dinheiros das rendas nom ouverem tam aginha aginha que o veedor he teudo de as poer by de sa cassa e depoys entregar-se quando veerem os dinheiros das rendas.

[8] Item manda El Rey que o veedor nom receba dinheiros nem pam nem vinho sem o scrivam nem o scrivam sem el.

[9] Item manda El Rey que o celeiro de pam tenha duas chaves e adega duas chaves e que oscrivam tenha bu na das chaves da adega e hũa das do celeiro.

[10] Item manda que aja by b ua arca de duas chaves em que ponham os dinheiros das rendas e que o scrivam tenha h na chave e o veedor tenha outra per tal guissa que a recepta e despesa seja bem recada $<d a>$ per esse scrivam. E mandem conta e recado cada buum ano a El Rey.

[11] Item manda que o veedor e o scrivam que ouverem de veer a dicta $<$ Gafaria $>$ que sejambomens boons e de boa fama e que sejam homeens que temam Deus e sas almas e que taaes homens devem a seer officiaes d'obra d' espitalidade.

[12] Item manda que esses que assy ouverem a ser officiaes que ante que sejam officiaes que ante El Rey seja certo per tres ou quatro bomeens boons da cidade de Coimbra jurados aos Santos Evangelhos se aqueles veedor e scrivam som homeens pera procurarem bem e dereytamente os beens da dita Gaffaria.

[13] Item manda El Rey que o veedor e o scrivam ante que comessem a procurar os bens da dicta Gaffaria que dem boons fiadores em mil libras per que coregam a dicta Gaffaria alg na coussa se contra elles for achado.

[14] Item manda El Rey que o veedor e o scrivam ajam cada buum ano dous dous moyos de trigo dous dous moyos de cevada e XX. Xx libras por vistir e de vinho enquanto durar na adega tal raşom como a huum gaffo e des que sayr o vinho da adega viii oyto dinheiros cada dia polo pam que by tomarem.

[15] Item manda que quando <forem $>$ a provar $<_{0}>$ pam e o vinho ou outras coussas que sejam a prol da dicta Gaffaria que combam das suas racoens.

[16]Estas som as pitanças que os gaffos am em que os saos nom am quinhom. Estas som as pitanças que os gaffos am en que os sãaos nom am quinhom. Primeiramente manda El Rey que a fruyta, os figos e olival da par da casa da Gafaria que o ajam os gaffos.

[17] Item manda El Rey que o cortinhal que esta a par da cassa que o ajam os gaffos pera seu folgoo.

[18] Item manda El Rey que os gaffos ajam pera pitanca iiii libras e buum almude de vinho a cada buum gaffo ou saam quando lhi derem primeiramente a raçom primeira.

[19] Item manda El Rey que dem aos gaffos por primeiro dia de Janeiro dous cantaros de vinho huum fryo e outro caente e b ua onça de pimenta e duas onças de cominhos e b ua quarta de mel e v soldos pera lenha. 


\section{Khronos, Revista de História da Ciência no 6, dezembro 2018}

[20] Item am-d' aver por dia d'ondoenças huum cantaro de vinho e v soldos pera lenha e dous soldos pera especiarias.

[21] Item am-d' aver por dia San Hoane buum almude de vinho e iii soldos pera especiarias e b'ua carega d' espadana.

[22] Item manda El Rey que os gafos [fl. 2] ajam a renda d' ermida de San Lourenco pera çapatos.

[23] Item am-d' aver todolos patos e capoes e frangaos que morem na Careira quando os aduzem os dos foros.

[24] Item manda que lhes dem bina enfusa que leva buum meyo almude de vinho de cada cuba por mostra.

[25] Item manda El Rey que lhe dem por dia de Natal huum cantaro de vinho e v soldos pera lenha e dous soldos pera especiarias.

[26] Item am quando vindimbam a vinha da par da cassa dous dous paães e senhas postas de carne e b'ua cesta d' uvas e am por dia de San Sisto dous dous cachos d' uvas e por vespera de Santa Maria d' Agosto outras tantas uvas.

[27] Item an-d' aver o veedor e o scrivam.

[28] Item quando podarem a vinha da par da cassa am-d' aver as vides todas della.

[29] Estes sam os foros e os custumes que os [ga]ffos an.

Primeiramente quando algum gafo more os panos de seu vestir e a sua calçadura quanto era vestido am o d'aver os gaffos pera b ú pitança que combam o dia que o soterarem.

[30] Item se ouver affanhas ou roupa de cama ou cousa que seja movil fazem d'el tres partes e as duas partes levara sa molher ou seu filho ou seu testamenteiro qualquer a que elle mande e a bu ua terça fica aos gaffos que o combam por sa alma e que o tragam em raçom.

[31] Item se o gafo ouver herdade dem a partir com sa molher e com seu filho se o ouver e a sa parte deve de ficar a cassa dous foros.

[32] Item quando buum alguum gafo ou saão entra primeiramente a raçom dar e receba dela nenh ua coussa deve a dar primeiro iïi libras e hum almude do melhor vinho vermelho que achar a vender na vila e nom levara bem dos dinheiros nem do vinho a qualquer pago.

[33] Item quando alguum quiser byr em romaria ou aa vila fazer de vestir ou de calcar ou per outra necessidade o veedor lhe deve dar licença.

[34] Item quando algum gafo ou gafa for a dicta villa sem licença deve pagar v soldos a outros seus companhões.

[35] Item quando nom for veer o Corpo de Deus quando diserem a missa v soldos.

[36] Item quando nom for aa oraçom $v$ soldos.

[37] Item se andar descalço pela quintãa $v$ soldos.

[38] Item se se alguum gafo chegar ao Paço page v soldos e esto se emende nos que am saúde que podem byr aa oraçom e aa igreja e nom querem ala hir.

Como deve o ser na gaffa $<$ ria $>$ b ua arca de duas chaves em que seja todalas scripturas também cartas d' El Rey como as outras todas. Outrosy he mandado per El Rey que seja brua arca de duas chaves dentro na cassa da Gafaria em que sejam as scripturas todas das herdades e das possissoes da dicta gafaria e que o veedor tenha bu u <das> chaves e os gafos a outra e quando ouverem mester alg ua scriptura que estem de deante ao meos dous gafos e que o scrivam the de huum alvara feito per sa mãao de quantas scripturas levarem e asiinaado 
pela mãao do veedor. [fl. 2v] E esto manda fazer El Rey por que foy certo que se perderam muytas scripturas por a malicia dos veedores que foram d' ante quando os tiravam do oficio com queixume que avyam e sunegavam as scripturas e perdian' as e per esta guissa ficava a Gaffaria delapidada sem escripturas e por esto mandou El Rey que os recadassem como dito he. $O$ am-d' aver.

\section{Aqui fala das rações que am os saos e do seu vestir quanto he e a seu tempo.}

Os sãaos am-d' aver < cada buum> cada ano buum moyo de trigo e vi quarteiros de segunda.

[39] Item enquanto durar o vinho na adega em a tal raçom contem <huum > gaffo e des que sayr o vinho nom am-d' aver dinheiros.

[40] Item manda El Rey que lhe dem cada huum ano per dia Sam Migel de Setenbro XL ${ }^{a}$ XL soldos pera vestir $e\left\langle X X>^{a} X X\right.$ soldos a cada hum pera lenha.

[41] Item manda El Rey a todallos sãaos que venha cada Domingo star a missa em na egreja da Gaffaria e o qual que by nom veer he mandado que lhe tolham hum alqueire de trigo do seu messadigo.

[42] Item manda El Rey que o sãao faça certo cada mes se des buu quer que for ou que venha per pessoa pera seerem certo se be vivo ou morto.

[43] Item se morer tam longe que nom possa viir mande seu recado certo.

Aqui fala como E1 Rey mandou que temperasem as rações aos saaos quando hy ouver pouco pan e pouco vinho.

Era de mil e CCC e LXXX e iiii anos. Seendo el-ey Dom Affonso na cidade de Coimbra primeiro dia do mes de Novembro da Era sobredicta mandou El Rey que quando fose pouco pam os sãos nom desem trigo nem segunda dobrada mays mandou que lhes desem xiii treze alqueires de segunda enquanto ouver no celeiro. [44] Item manda El Rey que enquanto durar o vinho na adega que dem a cada bum são brua meya de vinho cada dia per raçom ee esto se entende nos que am raçom de sãao e que moram fora da Gafaria.

\section{Aquy falla da carne e do pesscado que am os gaffos e os sãos polo ano.}

Os gaffos e os sãos manda El Rey que lhes dem dous porcos por dia de Natal que custem ambos viii libras.

[45] Item manda que lhis dem huum porco em dia d' Entrudo.

[46] Item manda que lhis dem XL ${ }^{a}$ soldos en dia de ciiza pera pe [sic] pescado.

[47] Item manda El Rey que lhis dem XL ${ }^{a}$ soldos por dia de lava-pes pera pescado.

[48] Item manda que lhis dem dous carneiros en dia de Pascoa.

[49] Item os gaffos an-d' aver as pelles e os deventres e as fresuras dos dictos carneiros.

[50] Item an-d' aver huum porco por vendimba.

[51] Item destes iiii porcos os gaffos an-d' aver as cabeças e os deventres e as fresuras e o unto de thes esta a-d' aver os gafos saos. E o al partisse perante todos como he de custume. Esta he a carne e o pescado e o conduyto que os gafos e os saos am cada buum ano.

[fl. 3] Aqui fala dos gaffos quando forem mal aviidos como o veedor e o scrivam os devem castigar.

[52] Item manda El Rey quando os gaffos pelejarem ou se diostarem que o mayoral e o scrivam os castigem e dem a cada buum seu dereyto. 


\section{Khronos, Revista de História da Ciência \\ № 6, dezembro 2018}

[53] Item manda El Rey que o sãao e o gaffo a que el fezer merce e na raçom da gafaria que logo faça dos seus beens que ouver de raiz a Gafaria.

[54] Item manda El Rey que quando algum gaffo entrar na raçom da dicta Gaffaria se for prove que nom tenha como de seu que lhe den o veedor buum almadraque e b'ua coberta de burel e buum cabeçal e o almadraque e o cabeçal sejam de lãa.

Aqui falla dos foros como devem ser pasados $<_{e}>$ en conto $<$ en na $>$ cassa da Gaffaria aos gaffos e aos $<$ sãaos $>$.

[55] Item manda El Rey que os patos e os capoes e os frangaos e os ovos e os coraziiis e as fogaças e os alhos e as cebollas e o linho e as legumbas e os porros e castanhas e nezperas. Que todo esto se parta em cad'buum ano per gaffos e per os mercieiros en na cassa da Gaffaria como be de custume.

Titulo segundo que fala das aldeas e das herdades e possissoes que a cassa da Gafaria de Coimbra ha todas pelo meudo(... $)^{7}$.

Conforme a Crise avança, a proteção se mantém e talvez aumente no reinado de Pedro I (1357-1367). Anos de Peste e fugas de camponeses para a cidade, onde se dedicam à vagabundagem, fazem este monarca confirmar e sancionar leis em prol dos leprosos, muitos deles na mesma situação dos camponeses: os gafos andantes.

Uma carta de mercê de D. Pedro, datada de 1365, se refere ao fato que, quando os leprosos chegavam "a cidade de Lixboa ou a Santarem ou a outros lugares do meu senhorio que os outros gafos que ham as raçoões e som vezinhos nos outros lugares os nom querem colher antre ssy e que outrossy os nom leixam pedir as esmollas por Deus em que se mantenham e que por a dicta razam elles e aquelles que som seus procuradores thes dam pancadas e feridas e os lançam fora das dictas villas e lugares".

Assim D. Pedro confirma os privilégios já concedidos por D. Afonso IV aos gafos andantes:

Dom Pedro etc. a todallas justiças dos meus regnos que esta carta virdes saude. Sabede que os gafos lazaros andantes ao mundo que nom ham raçam nas gafarias me enviaram dizer que quando chegamalg uas vezes a cidade de Lixboa ou a Santarem ou a outros lugares do meu senhorio que os outros gafos que ham as raçoões e som vezinhos nos outros lugares os nom querem colher antre ssy e que outrossy os nom leixam pedir as esmollas por Deus em que se [fl. 112] mantenham e que por a dicta razam eles e aquelles que som seus procuradores thes dam pancadas e feridas e os lançam fora das dictas villas e lugares e pero lhes mostram cartas d'el rey dom Afomso meu padre e minhas que lhas nom queredes guardar pella guisa que em ellas he contheudo no que dizem que recebem agravamento e pediam-me por mercee que lhes ounese a ello remedio. E eu veendo o que me assy pedir enviarom e querendo-lhe fazer graça e mercee porque elles som proves e nom teem outra vivenda salvo per suas esmollas tenho por bem e mando-vos que vós nom sofrades aos dictos gafos nem aos seus procuradores nem a outros que lhes ponha $[\mathrm{m}]$ embargos nehuuns sobre as dictas cousas nem lhes façam mal nem desaguisado

${ }^{7}$ Ibidem, pp. 87-91

${ }^{8}$ Instituto dos Arquivos Nacionais Torre do Tombo - Chancelaria de D. Pedro I, liv. 1, fl. 111v-112. 
nebuum por a dicta razam e se lho alguem fizer vós stranhade-lho de guisa que nom venham a mim mais agravar por a dicta razom se nom a vós me tornarey como aaqueles que som desobedientes contra mandado de seu senhor e mando que lhe sejam aguardadas as dictas cartas do dicto meu padre e minhas e dos reis que ante mim forom per a guisa que em ellas he contheudo porque vos mando que lhes leixees pedir suas esmollas em que se mantenham per as dictas villas e lugares de todo o meu senhorio emquanto minha mercee for. Umde al nom façades. Dante em Santarem xxy dias de Mayo el rey o mandou per Afomso Dominguez seu vasallo nom seendo bi Joham Goncallvez seu companhom. Stev'Eanes a fez [era] de mil iïjc e tres annos.'

Anos antes, em 1357, ao assumir a Coroa, enviara uma Carta de Mercê dirigida aos alvazis de Coimbra a favor da gafaria dessa cidade, proibindo que se tomasse palha, galinhas ou cabritos aos lavradores das herdades que a referida gafaria tinha em Rio de Vide ${ }^{10}$.

Dom Pedro pella graça de Deus rey de Portugal e do Algarve a vós alvaziiis da cidade de Coimbra e a todallas outras minhas justiças que esta carta virdes saude. Sabede que os gafos da Gafaria desse logo me enviarom dizer que elles ham seu mantiimento das herdades que essa Gafaria ha que som em logo que chamam Rio d'Avide que lhes os reis dante mim e eu demos e que tambem do meu e da raynha e dos iffantes como doutras pesoas lhes vaao hi tomar a palha e as galinhas e os cabritos e lhes nom leixam mantiimento pera seus boois e gaado e que tamanho be o dampno que ende recebem os dictos lavradores que lhes querem leixar as suas herdades de que se a elles segue grande dampno e nom podem dellas aver mantiimento. E que pero eu mandey apregoar que nehuum nom fosse allo tomar as dictas cousas o nom leixarom porem de fazer e pediam-me sobre ello mercee. E en veendo o que pediam e querendo-lhe fazer graça e mercee tenho por bem e mando que nebuum do meu pasto nem da rainha nem dos iffantes nem de ricomem nem de rica dona nem de neb ua outra pesoa nom tome aos lavradores das dictas herdades palha nem galinhas nem cabritos nem lhe façam outro desaguisado nehuum e se lhasfilharem e fezerem outro desaguisado nom tho consentades e stranhade-lho e fezede-lho correger gravemente como no fecto couber. Umde al nom façades sob pena dos meus encoutos e os dictos gafos tenham esta carta. Dante em Arganil ij dias de Novembro el rey o mandou per mestre V asco das Leis e per Joham Stevez. seus [fl. 82v] vasallos. Lopo Afomso a fez era de mil iijc $\mathrm{IR} v$ annos. ${ }^{11}$

O reinado de D. Fernando é marcado pelo desabastecimento provocado pelas sucessivas guerras com Castela. Assim mesmo promulga, em 1367, uma Carta de Confirmação dirigida ao vedor e ao escrivão da Gafaria de Coimbra, ordenando que dessem mensalmente aos gafos e aos sãos da dita gafaria determinadas quantias de trigo, segunda, vinho e dinheiros, de acordo com o estipulado na ordenação concedida a esta instituição por D. Afonso IV:

${ }^{9}$ Ibidem.

${ }^{10}$ Ibidem, liv. 1, fl. 82-82v.

${ }^{11}$ Ibidem. 


\section{Khronos, Revista de História da Ciência}

no 6, dezembro 2018

'Dom Fernando etc. A vós Galvam Perizveedor e a Domingu'Eanes scripvam da gafaria de Coinbra e outros quaeesquer que hi depos vós forem veedor e scripvam saude. Mando-vos que dedes a Joham das Laranjas e a Domingos d'Aveiro e a Afomso Periz natural d'Almalagues e a Domingo natural de Cantanhede e a Costança Lourenço natural d'Aveiro e a Maria Gonçallvez. molher que foe de Pero Carneyro e a Stevam Fernandiz natural de Mortaagoa e a Giraldo natural de Coja e a Joham do Pedrogam e a Maria Afonso < natural e > morador que foe em Evora e a Domingos do Valle natural de Galiza gafos em cada huum mês quatro 31 alqueires de trigo e dous dous 32 alqueires de segunda pella medida que ora corre.

E emquanto hi vinho ouver desa Gafaria senhas meas e nom mais e des que o hi nom ouver dade-lhe viij viij 33 dinheiros cada dia e as outras cousas que som contheudas na hordinhacam que os dictos gafos teem que faz mençam que foe <feita per> d'el rey dom Afomso meu avoo a que Deus perdoe.

Outrossy vos mando que dedes a Domingos Fernandiz de Condeixa e a Joham Martinz o cego e a Joham Afomso e Stevam Migueez, tecellam e a Johaam Periz e a Martim Galego e a Martim de Lamego cozinheiro que foe d'el rey meu padre a que outrossy Deus perdoe e a Girald'Eanes e a Stevam Ribeiro e a Gomez. Lourenço e a Domingas molher que foe de Gonçalo que se obrigava a servir os dictos gafos saaos por esmolla dos novos desa Gafaria quatro quatro 34 alqueires de trigo polla sobredicta medida que ora corre e mais nom. E todo o al que os saaos soyam a aver seja pera o vestir dos dictos gafos pero que os sobredictos saaos ajam parte dos porcos pella guisa que he contheudo na dicta hordinaçam e nom dedes a outro nenh u raçam sem meu mandado. E estes a que ha mandado dar obriguem-se que a sua morte leixem a dicta casa a sua direita parte que lhe acontecer de todos seus [fl. 15v] beens pera ajuda de manteer os dictos pobres.

Outrossy vos mando que provejades e procuredes e aministredes bem e fielmente os beens da dicta Gafaria e dedes aos sobredictos gafos e saaos todo aquello que vos por mim he mandado pella guisa que devedes e be contheudo em esta minha carta e em a hordenaçom sobredicta e tomedes pera vós aquello que be contheudo na dicta hordenaçam e mais nom. E mando a Domingos Alvo almoxarife e a Fernand'Afomso scripvam que vos constranga que façades as dictas cousas e nom vos consentam que façades o contrairo e que corregam aos sobredictos gafos e saãos todollos agravamentos que lhes fizestes ata aqui ou fezerdes des aqui en diante et vos façam fazer aquello que virem que he serviço de Deus e prol desa casa da Gafaria unde vós e elles al nom façades. Dante em Coinbra xxix dias de Julho el rey ho mandou per Alvaro Paaez seu vasallo Afomso Stevez a fez era de mil iiijc e cinque anos ${ }^{12}$.

É muito significativo que em época de crise alimentar, de devastação de colheitas, se reitere os privilégios de começos do século, comprovando a ação caritativa (motivada pela esperança de redenção final?) desses monarcas que privilegiam os leprosos em detrimento do restante da população.

Uma vez examinada a ação régia em favor de gafos e gafarias, retomemos a questão de sua alimentação. A caridade se impõe com esta doença, no sentido de tentar curar, ou ao menos estabilizar, essas imagens vivas do pecado para o benefício da coletividade.

12 Instituto dos Arquivos Nacionais Torre do Tombo - Chancelaria de D. Pedro I, liv. 1, fl. 111v -112. 
Fundada em 1210 pelo rei D. Sancho I, a Gafaria de Coimbra incluía entre as suas práticas a de garantir aos seus doentes sustento alimentar. Mas, só no século XIV, mais de um século após a sua instituição, é que este hospital obteve de D. Afonso IV, em 1329, um documento normativo que regulou o seu funcionamento e no qual se descreve pormenorizadamente a ração entregue aos leprosos ao longo do ano, como vimos acima. Mais tarde, em 1346, o mesmo rei acrescentou algumas cláusulas que alteraram a ração dos merceeiros sãos e introduziram novas pitanças ${ }^{13}$, a partilhar entre os leprosos e sãos ${ }^{14}$.

O objetivo deste diploma passava por solucionar alguns problemas relacionados com o sustento dos doentes, decorrentes dos abusos cometidos pelos administradores da gafaria. Ainda antes, em 1326 por meio de uma carta régia, sabemos que alguns leprosos se queixaram àquele monarca que o vedor e o escrivão do hospital não lhes davam as rações como deviam. Terá sido como resposta a estas queixas que D. Afonso promulgou o regimento, pois no seu prólogo o rei deixou bem claro que a sua elaboração se devia à denúncia que os leprosos lhe dirigiram, segundo a qual "nom eram bem onde é referido que os gafos e merceeiros sãos se queixaram ao rei de que nom eram bem mantehudos segundo as herdades e as possisoes e as rendas dellas que a dicta gafaria avy"15.

Ana Rita Rocha demonstrou que a gafaria de Coimbra era proprietária de vastos bens imóveis, em Coimbra e no seu termo, que lhe garantiam avultadas rendas anuais, suficientes para sustentar os seus doentes, demonstrando que o problema estava realmente relacionado com a sua gestão ${ }^{16}$.

\section{Alimentar e proteger}

E como foram alimentados os leprosos em tempos difíceis?

O Regimento da Gafaria do Hospital de São Lázaro de Coimbra, anteriormente citado, mostra a preocupação com o sustento alimentar a que os doentes tinham direito sempre que o rei lhes fazia mercê e eram admitidos no hospital. Trata-se da base da dieta dos leprosos de Coimbra, composta por um conjunto de alimentos característicos da nutrição medieval, como o pão, o vinho e o azeite. A estes produtos somam-se muitos outros com que os pacientes de S. Lázaro eram beneficiados ao longo do ano, as designadas pitanças, distribuídas em datas significativas e que enriqueciam a sua dieta.

\footnotetext{
13 Pitança: De Píetas se disse Pitança, que era um prato além da ração ordinária, in VITERBO, Joaquim de Santa Rosa de - Elucidário das palavras, termos e frases que em Portugal antigamente se usaram e que boje regularmente se ignoram : obra indispensável para entender sem erro os documentos mais raros e preciosos que entre nós se conservam / Publicado em Beneficio da Litheratura Portugueza Por Fr. Joaquim de Santa Rosa Viterbo. II - $2^{a}$ ed. revista, correcta e copiosamente addicionada de novos vocábulos, observações e notas críticas com um indice remissivo. - Lisboa: A. J. Fernandes Lopes 1865, p. 148.

14 ROCHA, Ana Rita. "A dieta dos leprosos numa gafaria medieval: o caso de Coimbra".

Revista de História da Sociedade e da Cultura 16". Coimbra, 2016, p. 65.

15 Ibid., p. 59.

16 AUC, Regimento do Hospital de S. Lázaro, Cofre, n 34, fl. 1, citado por Ana Rita Rocha, p. 59.
} 
Os leprosos recebiam uma grande quantidade anual de cereal: a cada doente eram entregues dois moios $^{17}$ de trigo e dois quarteiros de cereal de segunda, não especificado, mas que podia ser milho (painço ou miúdo), centeio ou cevada. Quando faltasse o trigo no celeiro, a sua quantidade era substituída pelo dobro da de cereal de segunda. A este pão somava-se, ainda, aquele que era distribuído por todos em forma de pitanças, nomeadamente dois pães, quando era vindimada a vinha da casa, e fogaças, durante a recessão dos foros, de acordo com o acrescento de 1346. Como é natural, os cereais que cada um recebia seriam transformados em pão. Tendo em conta que, já no século XV, segundo os tabelamentos do pão apresentados por Oliveira Marques, o peso de um pão podia oscilar entre $150 \mathrm{~g} \mathrm{e} 750 \mathrm{~g}{ }^{18}$, isto significa que os gafos recebiam quantidades muito elevadas de cereal, que correspondiam a uma média diária individual de $5 \mathrm{~kg}$ entre pão branco e escuro.

É muito importante que comparemos estes valores com os apresentados por Maria Helena da Cruz Coelho para o campesinato de Coimbra, que variavam entre $1 \mathrm{~kg}$ e $2 \mathrm{~kg}$ de pão por dia! ${ }^{19}$

Assim, os leprosos de Coimbra tinham acesso a uma alimentação muito superior à média das camadas mais baixas da sociedade. O mesmo se comprova quando comparamos os valores de Coimbra com os de leprosarias de outros países, nomeadamente França, onde o consumo diário de pão variava também entre $1 \mathrm{~kg}$ e $2 \mathrm{~kg}^{20}$.

De fato, mesmo numa época de crise estamos na presença de um exagerado consumo de pão.

O vinho ocupava, tal como o pão, um lugar fundamental na ração diária dos pacientes da Gafaria de Coimbra. Inclusivamente, o próprio hospital possuía no seu espaço, "da par da cassa", uma vinha, cuja vindima era motivo para novas pitanças. Sendo esta uma região mediterrânica, é natural que a cultura do vinho estivesse bem presente. O vinho era utilizado tanto para acompanhar refeições, como para saciar.

Cada doente recebia, diariamente e enquanto houvesse na adega, "bua meya e meya doutra meya de vinho", como diz o regimento acima citado, que equivalia a pouco mais de 3 litros.

${ }^{17}$ Uma vez que, em Coimbra, 1 alqueire equivalia a cerca de $10 \mathrm{~kg}$; um moio (64 alqueires), a $640 \mathrm{~kg}$; e um quarteiro (16 alqueires) a $160 \mathrm{~kg}$, cada leproso recebia, por ano, à volta de $1.825 \mathrm{~kg}$ de cereal, que correspondia a uma média diária de $5 \mathrm{~kg}$. Para a conversão de medidas medievais em medidas atuais, ver COELHO, 1990: 18, n. 8.

${ }^{18}$ MARQUES, A. H. de Oliveira. A sociedade medieval portuguesa. Aspectos de vida quotidiana. $6^{\text {a }}$ ed. Lisboa: A Esfera dos Livros, 2010, p. 36.

${ }^{19}$ COELHO, Maria Helena da Cruz, "Apontamentos sobre a comida e a bebida do campesinato coimbrão em tempos medievos". In: Homens, espaços e poderes (séculos XI a XVI). Vol. 1: Notas do viver social. Lisboa: Livros Horizonte, 1990, pp. 12-15.

${ }^{20}$ ROCHA, Ana Rita, op. cit., p. 60. 
Faltando esta bebida na gafaria, os leprosos eram compensados com oito dinheiros cada um para o comprarem. Mas a quantidade de vinho recebida não se limitava a esta descrita acima. Sempre que um leproso ou são era admitido, todos os outros recebiam dele, de pitança, um almude (17 litros) e ao longo do ano, através de outras pitanças, tinham ainda direito a vários cântaros distribuídos por cinco datas diferentes: Ano Novo, Endoenças, S. João, prova do vinho e Natal.

Avançando no século XIV, a ração de cereal e vinho dos leprosos sofreu alterações em suas quantidades e na periodicidade de entrega. Esta mudança era já uma realidade em 1367, quando o rei D. Fernando concedeu a doze leprosos uma ração individual composta por quatro alqueires (cerca de $40 \mathrm{~kg}$ ) de trigo e dois alqueires (aproximadamente $20 \mathrm{~kg}$ ) de cereal de segunda, mensais, e uma meia, que constituem por volta de 2,1 litros, de vinho por dia, enquanto tudo o resto se mantinha como na ordenação de D. Afonso IV.

Isto resultará que os gafos de Coimbra tinham agora acesso a cerca de $2 \mathrm{~kg}$ de cereal e 2,1 1 de vinho quotidianos, uma significativa redução em relação às quantidades definidas em 1329. Alguns documentos posteriores do mesmo rei, reunidos num traslado de 1383 , comprovam que houve diminuição das rações, deixando transparecer a ideia de escassez provocada por maus anos agrícolas e baixos rendimentos da instituição; redução motivada pelas crises agrícolas e pelas guerras que marcaram o reinado fernandino e que deslocavam imensos recursos.

A dieta de base, que incluía pão e vinho, completava-se com uma quantidade anual de azeite e de sal. No primeiro dia do ano, era entregue a cada leproso um alqueire de cada um dos referidos produtos. Embora o seu consumo pudesse ser desigual ao longo do ano, podemos afirmar que, em média, cada doente teria acesso a $40 \mathrm{ml}$ de azeite e $30 \mathrm{~g}$ de sal diários.

\section{As pitanças}

O sustento dos habitantes da Gafaria de Coimbra não se resumia aos produtos que temos vindo a descrever, completando-se com um conjunto de alimentos extraordinários, entregues sob a forma de pitanças, sobretudo em dias de festa ou em datas relacionadas com os trabalhos agrícolas. Distribuídas a todos os leprosos e não individualmente, as referidas pitanças quebravam a monotonia de uma ração diária composta apenas por pão e vinho. Por meio delas, os doentes tinham acesso a produtos indispensáveis a uma alimentação saudável, como as frutas, os legumes e a carne, mas também a outros ingredientes menos comuns, como as especiarias, que davam um gosto diferente às refeições. No que diz respeito a frutas e legumes a que os leprosos tinham direito, o regimento contém pouca informação. Apenas é indicado que, por ordem do rei, aqueles ficariam com a fruta, os figos e o olival contíguo ao hospital:

"Primeiramente manda el rey que a fruta e os figos e olival da par da cassa da 
gaffaria que o ajam os gaffos", conforme o regimento acima.

Os gafos também recebiam algumas pitanças de pão e vinho, a que já nos referimos a propósito da ração individual.

Ainda no texto de 1329, na cláusula em que D. Afonso IV “manda (...) que o cortinhal que esta a par da cassa que o ajam os gaffos pera seu folgar" (Item 17).

Em datas festivas os gafos de Coimbra recebiam determinadas quantidades de especiarias ou dinheiro para as comprarem.

Assim, nas Endoenças, ou seja, nas celebrações da Quinta-feira Santa, eram-lhes entregues dois soldos para especiarias, sem indicação das variedades a distribuir, aos quais se acrescentavam três soldos, no dia de S. João, e outros dois soldos, no dia de Natal, para o mesmo fim. Seria um grande privilégio receber estes produtos, mesmo em quantidades reduzidas, numa época em que o seu consumo era atributo das camadas superiores ${ }^{21}$.

Apenas no Ano Novo eram particularizadas as especiarias a dar aos leprosos. Neste dia, os doentes de S. Lázaro recebiam uma onça, ou seja, cerca de $30 \mathrm{~g}$ de pimenta e duas onças (60g) de cominho.

A quantidade expressiva das rações acrescidas de carne, peixe, hortaliças e frutas e do extremo luxo de receberem especiarias, ainda que na qualidade de pitanças, nos mostra uma doença que é quase uma hierofania, uma materialização da cólera e da bondade divinas.

Nos duros tempos da Crise, encontra-se comprovada a extrema proteção real aos gafos, resultado de, como foi dito antes, uma postura caritativa, mas que só pode ser explicada tendo em conta o espaço ocupado no imaginário medieval, pela figura do leproso, misto de horror e atração que lembra aos homens da corrupção da carne e da danação eterna. Mesmo num país violentamente tumultuado por fomes, peste e guerras quase contínuas, os gafos são os privilegiados, "santos-pecadores" que apontam aos homens as misérias de cair no desagrado divino e ao mesmo tempo concedem-lhes a oportunidade de redenção através do exercício da caridade.

${ }^{21}$ Ibidem, p. 65. 